
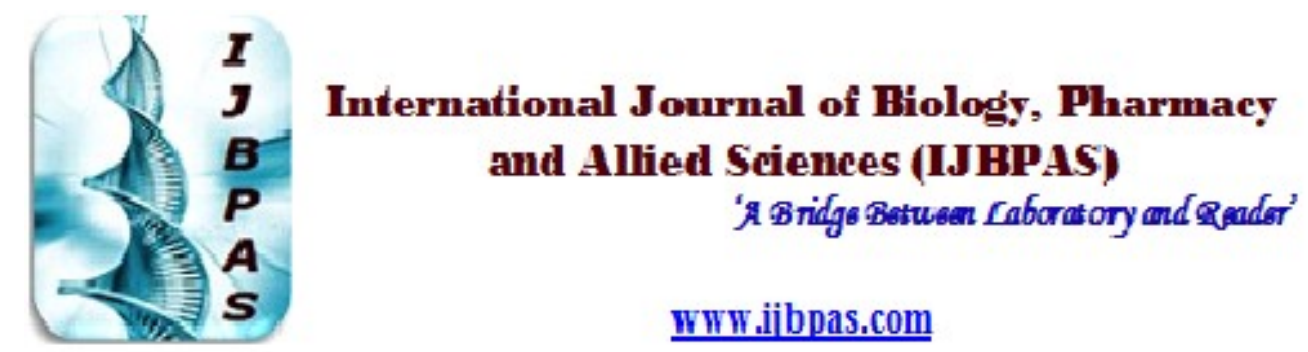

WWW.ijbpas.com

\title{
TANDEM MASS SPECTROMETRIC METHOD FOR THE DETERMINATION OF GENOTOXIC IMPURITYETHYL BENZENE SULFONATE IN AMLODIPINE BESYLATE
}

\author{
SUSARLA $\mathbf{S}^{1^{*}}$, DUVVURI ${ }^{1}$ AND RAO BM ${ }^{2}$ \\ 1: GITAM (Deemed to be University), Visakhapatnam, Andhra Pradesh, India \\ 2: Dr Reddy's Laboratories, Hyderabad, India
}

*Corresponding Author: Sivakumar Susarala: E Mail: shivakumarsdoer@gmail.com Received $13^{\text {th }}$ June 2020; Revised $15^{\text {th }}$ July 2020; Accepted $12^{\text {th }}$ Aug. 2020; Available online $1^{\text {st }}$ May 2021

\section{https://doi.org/10.31032/IJBPAS/2021/10.5.5452}

\begin{abstract}
A highly sensitive method for the quantification of genotoxic impurity Ethylbenzene sulfonate (EBS) in Amlodipine Besylate using hyphenated techniques has been developed. EBS is assessed by LCMS/MS method in selected ion monitoring mode (SIM) using Shodex C $18(150 \times 4.6 \mathrm{~mm}) 5.0 \mu \mathrm{m}$ column. $0.01 \mathrm{M}$ ammonium acetate is used as buffer and its admixture with acetonitrile in the ratio: $60: 40(\mathrm{v} / \mathrm{v})$, is found to be an effective mobile phase A and with the buffer and acetonitrile in the ratio: 5:95 (v/v) as mobile phase $\mathrm{B}$. The gradient program $(\mathrm{T} / \% \mathrm{~B})$ is set as $0 / 5,2.00 / 5,4.00 / 50,8.00 / 70$, 10.00/95, and 15.00/95. The developed method has been validated as per International Conference on Harmonization guidelines. The LOD and LOQ values of EBS are found to be $0.01 \mu \mathrm{g} / \mathrm{mL}$ and 0.04 $\mu \mathrm{g} / \mathrm{mL}$ respectively. Method has accuracy within $98.1-103.0 \%$ for the analyte. This method is costeffective, direct, accurate and convenient quality control tool for determination of EBS in Amlodipine Besylate.
\end{abstract}

Keywords: Amlodipine besylate, Ethyl benzene sulfonate (EBS), genotoxic, Selected ion monitoring (SIM)

\section{INTRODUCTION}

Amlodipine besylate (Figure 1a) 3-Ethyl 5-methyl (4RS)-2- [(2-aminoethoxy) methyl]-4-(2-chlorophenyl)- 6- methyl-1,4dihydropyridine $\quad-3, \quad 5$-dicarboxylate benzenesulfonate, is a drug belonging to calcium channel blockers (CCBs) [1] and is used to treat hypertension. The molecule contains one chiral carbon atom and exists as a racemic mixture but only the (-) -(S)enantiomer of amlodipine shows the $\mathrm{CCB}$ 
effect $[2,3]$. Amlodipine is an intrinsically long-acting, vaso-selective dihydropyridine calcium antagonist that inhibits calcium ion influx across cell membranes selectively, with a greater effect on vascular smooth muscle cells than on cardiac muscle cells. Active pharmaceutical Ingredients prone to contain different impurities that may arise from starting materials, reagents employed for the synthesis and by products in the synthetic process. Some of these impurities are mutagenic or carcinogenic in nature, which make these impurities to consider critically eliminating them from the final drug product [4]. Often different synthetic process related modifications are employed to remove these impurities, yet it became impossible to completely eliminate the impurities from the final drug substances. According to the guidance of drug regulatory authorities, it is crucial to regulate the level of genotoxic impurities in the drug substances based on the daily dose $[5,6]$.

Sulfonic acid esters are categorized as potentially genotoxic impurities (PGIs) in pharmaceuticals. The presence of any alcohol either in any of the stages of synthesis, or the crystallization stage of the salt may cause the formation of sulfonic acid esters. Ethyl benzene sulfonate (EBS) (Figure 1b) is such kind of impurity that has been characterized as potentially genotoxic and it has the regulatory limit of intake at $1.5 \mu \mathrm{g} / \mathrm{day}$ [7]. PGIs are known to induce genetic mutations or chromosomal aberrations and are reported as known carcinogens in rats and mice [8]. The potential presence of these genotoxins has attracted the attention of regulatory authorities. European Medicines Agency's (EMEA) Committee for Medicinal products for Human use (CHMP) has published guidelines regarding limits of genotoxic impurities [9]. In 2008, US FDA has also come up with the draft guidelines on genotoxic and carcinogenic impurities in drug substances and products. These guidelines describe ways to reduce the potential lifetime cancer risk associated with patient exposure to genotoxic and carcinogenic impurities and the ways to reduce them. Based on the current regulatory guidance for genotoxic impurities, analytical methods should be developed to meet the required limit of $1.5 \mu \mathrm{g} /$ day daily intake of individual impurity [10, 11]. The limit of EBS in amlodipine besylate is $150 \mathrm{ppm}$ calculated on the basis of maximum daily dose.

In accordance with the amplifying concerns of regulatory authorities regarding the control of genotoxic impurities in pharmaceuticals, an attempt has been made in the present investigation to develop a sensitive LC-MS/MS method to determine the Ethyl benzene sulfonate in very low levels in Amlodipine besylate. 


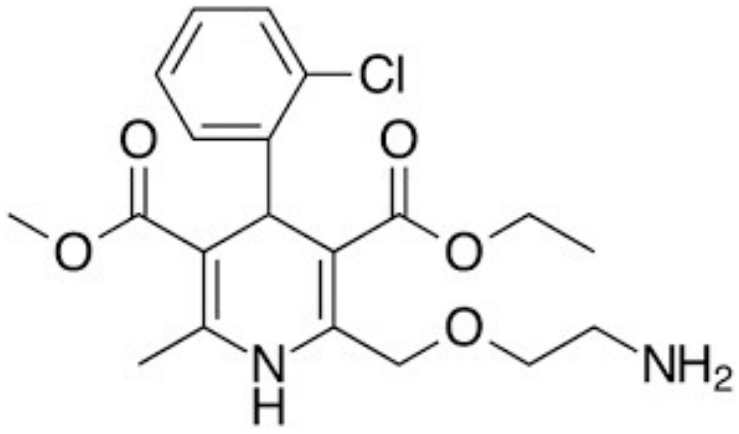

(a)

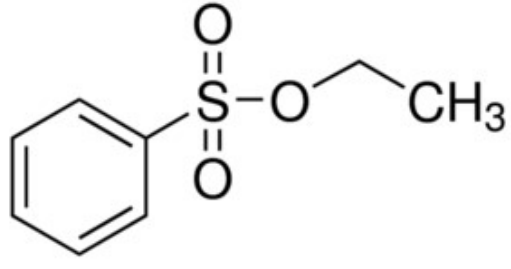

(b)

Figure 1: (a) Amlodipine (b) Ethyl benzene sulfonate (EBS)

\section{MATERIALS AND METHODS}

\section{Materials}

Ethyl Benzene Sulfonate (EBS) was obtained from Sigma Aldrich, Bangalore, India. Analytical grade ammonium acetate and acetonitrile were purchased from Merck, India. Amlodipine Besylate was procured from Mylan Laboratories Ltd. Hyderabad.

\section{Chromatographic conditions}

The chromatographic system used was Shimadzu LCMS 8040. The analytical column was Shodex C $18(150 \times 4.6 \mathrm{~mm}) 5.0$ $\mu \mathrm{m}$ column. $0.01 \mathrm{M}$ ammonium acetate was used as buffer. The mixture of buffer and acetonitrile in 60:40 (v/v) ratio was used as mobile phase $\mathrm{A}$ and that of buffer and acetonitrile in 5:95 (v/v) ratio was used as mobile phase $\mathrm{B}$. The gradient program $(\mathrm{T} / \% \mathrm{~B})$ was set as $0 / 5,2.00 / 5,4.00 / 50$, $8.00 / 70,10.00 / 95$, and $15.00 / 95$. The flow rate of the mobile phase was kept at 1.0 $\mathrm{mL} / \mathrm{min}$. Column oven temperature and auto sampler temperature were set as $30^{\circ} \mathrm{C}$ and $25^{\circ} \mathrm{C}$, respectively and injection volume was $20 \mu \mathrm{L}$. Instrument operation, data collection and processing were done by LCMS Lab Solutions.

\section{Mass spectrometer conditions}

Typical operation settings were as follows: capillary voltage, $3.5 \mathrm{KV}$; sample cone, $25 \mathrm{~V}$; source temperature, $120{ }^{\circ} \mathrm{C}$; desolvation temperature $350{ }^{\circ} \mathrm{C}$; cone gas flow rate $50 \mathrm{~L} / \mathrm{Hr}$; desolvation gas $\left(\mathrm{N}_{2}\right)$ flow rate $1000 \mathrm{~L} / \mathrm{Hr}$, Argon as CID gas for MS/MS experiments. The selective ion monitoring (SIM) was selected for quantification of EBS. Venting was done using valco valve (Valco Instruments Co. Inc., VICI AG International). Venting was given from $6.1 \mathrm{~min}$ to $15.0 \mathrm{~min}$.

\section{Standard solution preparation}

$0.15 \mathrm{mg} / \mathrm{mL}$ concentrated stock solutions of the EBS was prepared by dissolving the $15 \mathrm{mg}$ of EBS $10 \mathrm{ml}$ of acetonitrile. $0.015 \mathrm{mg} / \mathrm{mL}$ diluted stock solution was prepared by diluting $1 \mathrm{~mL}$ of the $0.15 \mathrm{mg} / \mathrm{mL}$ solutions to $10 \mathrm{~mL}$ with 
acetonitrile. The working standard solutions of $0.15 \mu \mathrm{g} / \mathrm{mL}$, were prepared from the diluted stock solution employing serial dilution method. The working standard solutions were always prepared fresh and injected immediately to the chromatographic system.

\section{Sample preparation}

Amlodipine Besylate sample solution of $1 \mathrm{mg} / \mathrm{ml}$ concentration was prepared by accurately weighing about $1 \mathrm{mg}$ of the drug substance into a HPLC vial and adding $1 \mathrm{~mL}$ of sample diluentacetonitrile, shaking to dissolve and then immediately injecting the resulting solution.

\section{Validation study}

The developed method for determination of EBS in Amlodipine besylate was validated according to the ICH guidelines. The linearity was evaluated by preparing and analyzing six calibrators of 0.009$0.3 \mu \mathrm{g} / \mathrm{mL}(9.0-300 \mathrm{ppm}$, corresponding to the concentration of $1 \mathrm{mg} / \mathrm{mL}$ of Amlodipine besylate) for EBS. The least squares linear regression analysis was performed to determine slope, intercept and regression coefficient. System precision of the mass spectrometric response was established by making six injections of the standard solution. By displaying precision, with the injection of lower concentrations of analyte in six replications, the LOQ and LOD were determined. The LOQ and LOD were calculated on the basis of the lowest concentration of compound that gives $\mathrm{S} / \mathrm{N}$ ration 10 and $\%$ RSD $<10$ (for LOQ) and $\mathrm{S} / \mathrm{N}$ ration 3(for LOD). The method precision was evaluated by spiking each analyte and determining the \%RSD. Accuracy was determined by spiking the known amount of EBS with known amount of sample in six different volumetric flasks and it was calculated after making corrections for the amount pre-existed in the sample. Stability of analytes in sample solution was done by analyzing spiked sample solution at different time intervals at room temperature.

\section{RESULTS AND DISCUSSION}

\section{Optimization of sample preparation}

In genotoxic impurities (GTI) analyses, sample preparation is a key exercise that has an effect on analyte stability, sensitivity, recovery, and matrix effect in trace analysis. Different diluents were evaluated with respect to extraction efficiency and chromatography. Acetonitrile was found to have good solubilization capacity for both the drug substance and analyte, EBS. Acetonitrile alone was not found suitable due to lower responses of the analytes and bad peak shape. Premix of acetonitrile and water in different ratios were evaluated. Good response, proper peak shapes and good recovery values were observed for the analyte EBS with the premixed solution of 50:50 (v/v) acetonitrile/water. 


\section{Column selection and separation}

Numerous kinds of stationary phases were evaluated to achieve appropriate separation of the analyte peaks from the drug substance peak. It was important to attain proper separation as the concentration of drug substance was high leading to broaden the peak. Various columns like Zorbax Rx C18, Shodex C-18 and Kromasil C18 of different dimensions were evaluated. Based on the less response and low resolution of analytes with the drug substance peak, it was found that the columns Zorbax Rx C18 and Kromasil C18 were not suitable. On Shodex C-18 column of dimensions $150 \mathrm{~mm} \times 4.6 \mathrm{~m}$ minternal diameter, $5.0 \mu \mathrm{m}$, separation and response for EBS was found to be good. On this column the analyte was well retained and separated from the drug substance peak of Amlodipine Besylate. Diverse composition of mobile phase using $0.1 \%$ formic acid ( $\mathrm{v} / \mathrm{v}$ in water), $0.1 \%$ acetic acid ( $\mathrm{v} / \mathrm{v}$ in water) and ammonium formate, with acetonitrile and methanol were studied. Decent response and separation were spotted with the combination of ammonium acetate buffer and acetonitrile in isocratic and gradient elution modes. The optimum separation of EBS and drug substance peaks were noticed in gradient elution mode. Flow rate of $1 \mathrm{~mL} / \mathrm{min}$ was maintained and the column was thermostated at $30^{\circ} \mathrm{C}$ to avoid any shift in retention time. However, prior to electrospray ionization, flow rate was reduced to $0.2 \mathrm{~mL} / \mathrm{min}$ using a splitter. Retention time of EBS were observed to be about 4.6 mins. Well separated Gaussian peak was resulted for EBS from the drug substance peak.

Peak corresponding to Amlodipine Besylate eluted at around $10 \mathrm{mins}$. Due to adequate separation of analyte and drug peaks, only the analyte EBS was allowed to enter the mass detector by venting the drug substance peak using switching valco valve. In this way matrix effect due to high concentration of drug substance was avoided and only the peaks of interest were monitored.

\section{Optimization of mass spectrometric parameters}

Choosing a detection method is the most important part of pharmaceutical analysis. Due to the insufficient sensitivity and specificity for the trace analysis of EBS with the HPLC-UV and GC-FID methods, sensitive and specific mass spectrometric detection of tandem LC/MS/MS was evaluated in SIM mode. This mode permits significant enhancement of selectivity and sensitivity for screening and quantification. In positive SIM mode, EBS ion mass peak was seen at 204.1 corresponding to [M + $18]^{+}=\left[\mathrm{M}+\mathrm{NH}_{4}\right]^{+}$. The LC-MS/MS SIM chromatograms of EBS are shown in Figure 2. 


\section{Validation of method}

The developed methods were validated as per ICH guidelines in terms of specificity, linearity, accuracy, limit of detection (LOD), limit of quantitation (LOQ), precision, robustness and the data are presented in Table 1.

\section{Specificity}

Method specificity was tested by injecting blank, amlodipine besylate, ethyl benzene sulfonate and ethyl benzene sulfonate spiked with amlodipine besylate sample separately and the resultant chromatograms were displayed in Figure 3. The specificity of the developed LC-MS methods was indicated by showing Ethyl benzene sulfonate peak was eluted at the retention time of $4.6 \mathrm{~min}$ with $\mathrm{m} / \mathrm{z}$ of 204.1 .

\section{Limit of quantification and Limit of detection}

In order to establish the limit of detection (LOD) and limit of quantification (LOQ) of the developed method the analyte concentrations were decreased by a serial dilution method up to a concentration level where the concentrations resulted in the $\mathrm{S} / \mathrm{N}$ ratio of 3 and 10 for LOD and LOQ respectively. With respect to the sample concentration of $1 \mathrm{mg} / \mathrm{mL}$, LOD and LOQ of ethyl benzene sulfonate were resulted as $0.003 \mu \mathrm{g} / \mathrm{mL}$ and $0.009 \mu \mathrm{g} / \mathrm{mL}$ respectively. The LOD and LOQ chromatograms displayed in Figure 4.

\section{Precision}

The precision of the methods was checked by injecting LOQ solutions $(0.009 \mu \mathrm{g} / \mathrm{mL})$ for six times and the data was depicted in Table 2. The values of RSDs for areas of each EBS were calculated. The \% relative standard deviation (\%RSD) was found to be below 3\% for EBS in system precision.

\section{Linearity}

The linearity of EBS was satisfactorily demonstrated with a six-point calibration graph between 0.009 and $0.3 \mu \mathrm{g} / \mathrm{mL}(9.0-$ $300 \mathrm{ppm}$ with respect to a sample concentration of $1 \mathrm{mg} / \mathrm{mL}$ ). Correlation coefficients for all analytes were $>0.996$ and the data are represented in Figure 5.

\section{Accuracy}

Accuracy of the developed LC-MS/MS method was demonstrated by percent recovery of ethyl benzene sulfonate, employing the standard addition method. Percent recovery values of ethyl benzene sulfonate were determined for triplicate injections of the LOQ concentration level, $50 \%, 100 \%$ and $150 \%$ concentrations of the specification limit of $0.15 \mu \mathrm{g} / \mathrm{mL}$ with respect to the aripiprazole sample concentration of $1 \mathrm{mg} / \mathrm{mL}$. Recoveries are in the range of $90.2-107.3 \%$ and the data are represented in Table 3. The results in Table 3 showed that the decent recovery values of ethyl benzene sulfonate were obtained in the range of $9.0 \mathrm{ppm}$ (LOQ 
level) to $225 \mathrm{ppm}(150 \%$ level) with \% RSD not more than 9 .

\section{Robustness}

By demonstrating the resolution greater than 2.0 between analyte and drug substance, robustness of the method was ensured when column temperature $\left( \pm 5^{0} \mathrm{C}\right)$, and mobile phase flow rate $( \pm 0.1 \mathrm{~mL} / \mathrm{min})$, were deliberately varied. Results of robustness study enumerated in Table 4.

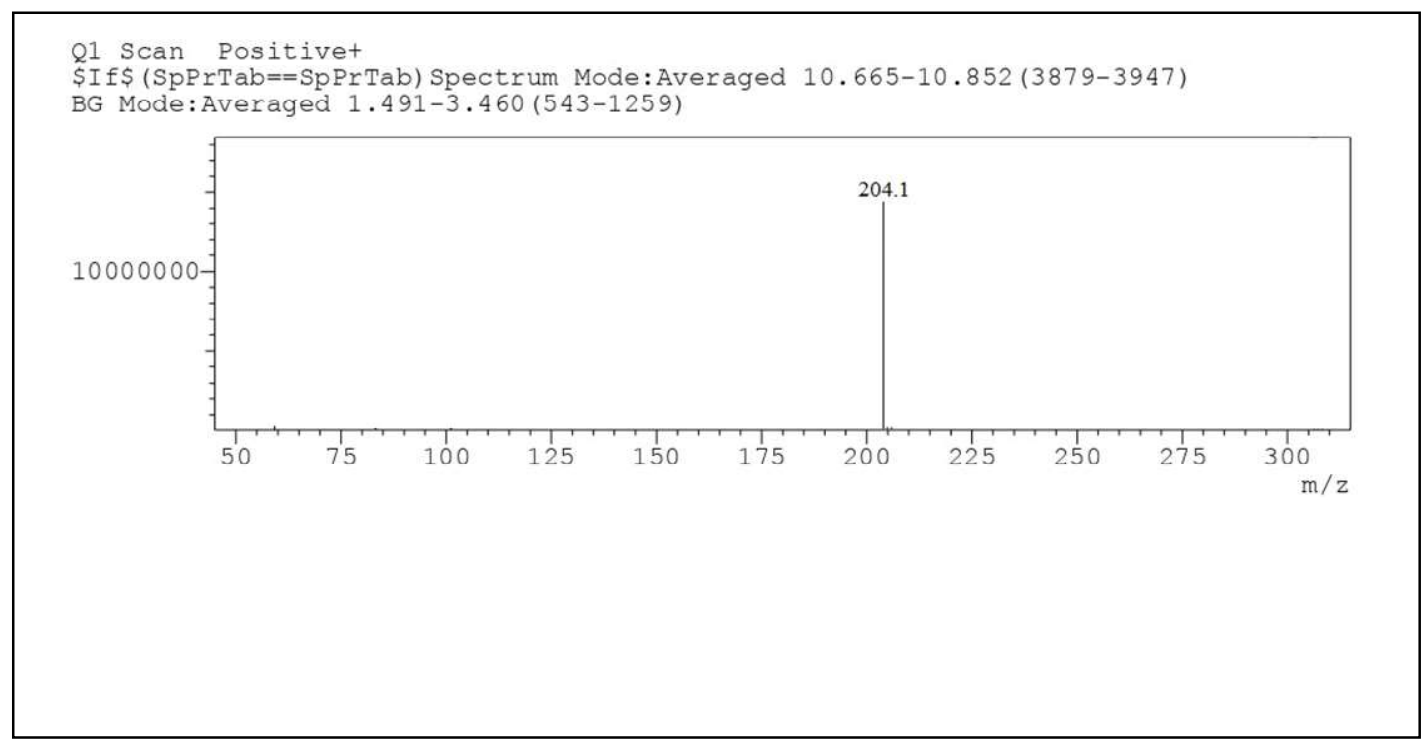

Figure 2: SIM Chromatogram of Ethyl benzene sulfonate

Table 1: Validation data for the determination of EBS

\begin{tabular}{|c|c|}
\hline Parameter & EBS \\
\hline LOD $(\mu \mathrm{g} / \mathrm{mL})$ & 0.003 \\
\hline LOQ $(\mu \mathrm{g} / \mathrm{mL})$ & 0.009 \\
\hline Precision at LOQ $(\mathrm{RSD} \%)$ & 1.02 \\
\hline Linearity range $(\mu \mathrm{g} / \mathrm{mL})$ & $0.009-0.23$ \\
\hline Correlation coefficient & $>0.996$ \\
\hline Accuracy at LOQ $($ Recovery $\%)$ & $\mathbf{9 0 . 2}-107.3$ \\
\hline
\end{tabular}
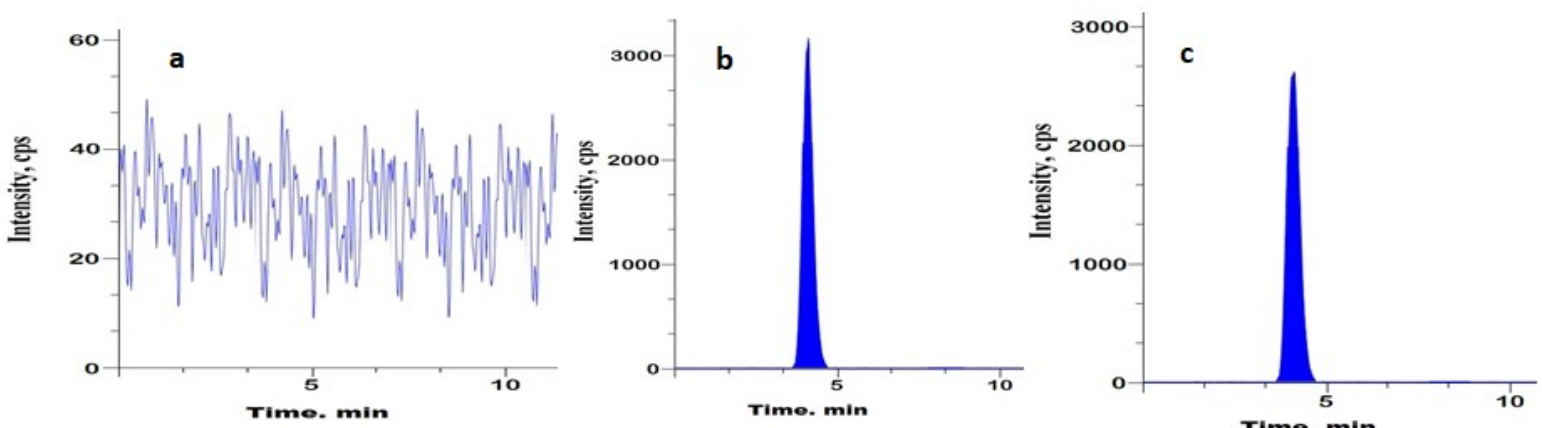

Figure 3: (a) Chromatogram of blank. (b) Chromatogram of standard containing $0.15 \mu \mathrm{g} / \mathrm{mL}(150 \mathrm{ng} / \mathrm{mL})$ of EBS. (c) Chromatogram of Aripiprazole sample spiked with Ethyl benzene sulfonate at $0.15 \mu \mathrm{g} / \mathrm{Ml}$ 


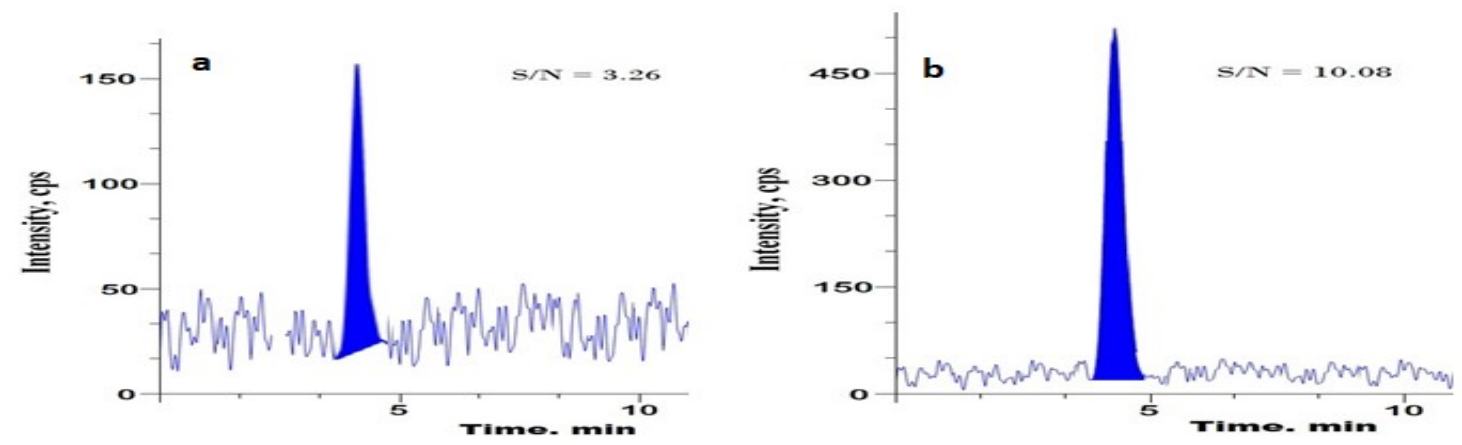

Figure 4: (a) Chromatogram of LOD. (b) Chromatogram of LOQ

Table 2: Precision data of ethyl benzene sulfonate

\begin{tabular}{|c|c|}
\hline Preparation & Area at LOQ level \\
\hline 1 & 540 \\
\hline 2 & 535 \\
\hline 3 & 512 \\
\hline 4 & 521 \\
\hline 5 & 550 \\
\hline 6 & 531 \\
\hline Average & 531.5 \\
\hline SD & 12.36 \\
\hline \%RSD & 2.33 \\
\hline
\end{tabular}

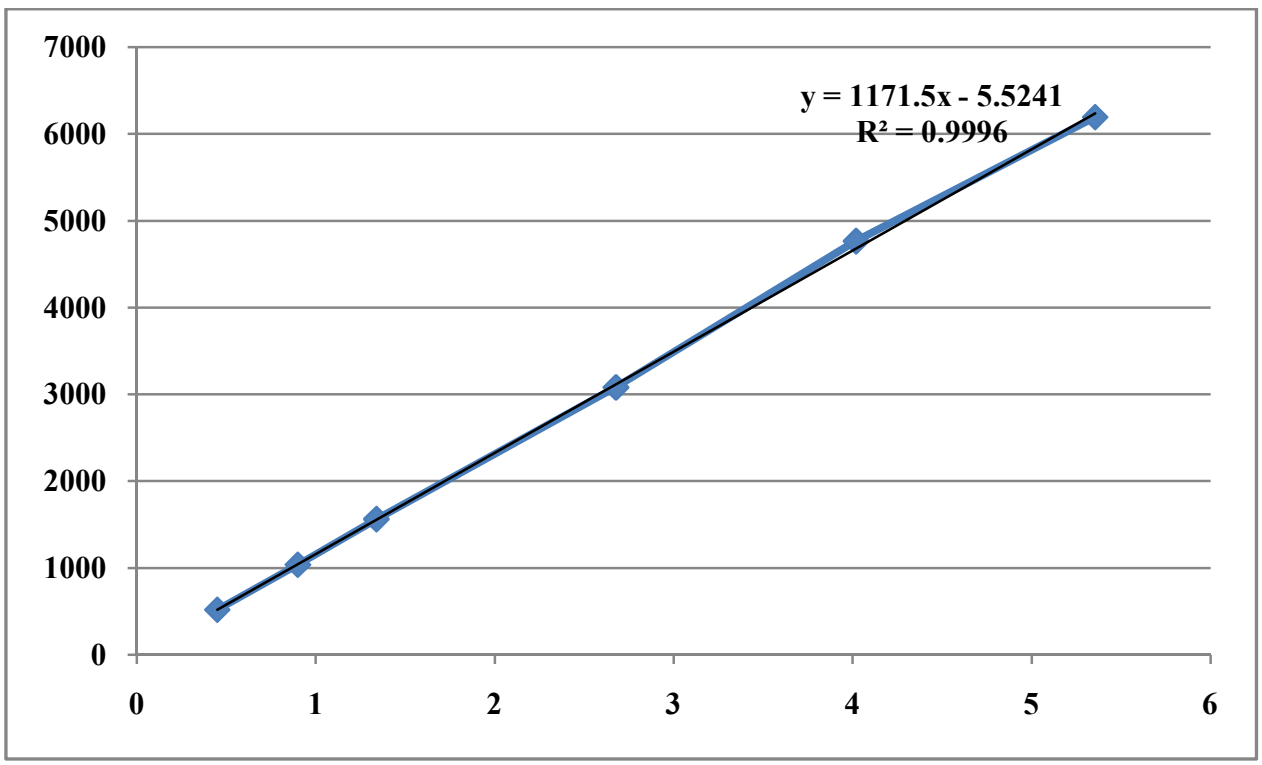

Figure 5: Linearity graph

Table 3: \% Recovery of Ethyl benzene sulfonate

\begin{tabular}{|c|c|c|c|c|c|c|c|c|}
\hline \multicolumn{3}{|c|}{ LOQ level } & \multicolumn{3}{|c|}{$100 \%$ level } & \multicolumn{3}{|c|}{$150 \%$ level } \\
\hline $\begin{array}{c}\text { Amount } \\
\text { Added } \\
(\mu \mathrm{g})\end{array}$ & $\begin{array}{c}\text { Amount } \\
\text { found } \\
(\mu \mathrm{g})\end{array}$ & $\begin{array}{c}\% \\
\text { Recovery }\end{array}$ & $\begin{array}{c}\text { Amount } \\
\text { Added } \\
(\mu \mathrm{g})\end{array}$ & $\begin{array}{c}\text { Amount } \\
\text { found }(\mu \mathrm{g})\end{array}$ & $\begin{array}{c}\% \\
\text { Recover } \\
\mathbf{y}\end{array}$ & $\begin{array}{c}\text { Amount } \\
\text { Added } \\
(\mu \mathrm{g})\end{array}$ & $\begin{array}{c}\text { Amount } \\
\text { found }(\mu \mathrm{g})\end{array}$ & $\begin{array}{c}\% \\
\text { Recove } \\
\text { ry }\end{array}$ \\
\hline 0.009 & 0.0082 & 91.8 & 0.15 & 0.160 & 107.3 & 0.225 & 0.233 & 103.9 \\
\hline 0.009 & 0.0081 & 90.2 & 0.15 & 0.137 & 91.9 & 0.225 & 0.221 & 98.4 \\
\hline 0.009 & 0.0095 & 105.8 & 0.15 & 0.158 & 105.6 & 0.225 & 0.237 & 105.4 \\
\hline \multicolumn{3}{|c|}{95.86667} & \multicolumn{3}{|c|}{101.6} & \multicolumn{3}{|c|}{102.5666667} \\
\hline \multicolumn{3}{|c|}{8.630952} & \multicolumn{3}{|c|}{8.443340571} & \multicolumn{3}{|c|}{3.685557398} \\
\hline \multicolumn{3}{|c|}{8.903079} & \multicolumn{3}{|c|}{8.310374578} & \multicolumn{3}{|c|}{3.59332863} \\
\hline
\end{tabular}


Table 4: Robustness results

\begin{tabular}{|c|c|c|c|}
\hline \multirow{3}{*}{ Parameter } & Variation & $\begin{array}{c}\text { \%RSD of Area at LOQ } \\
\text { level }\end{array}$ & $\begin{array}{c}\text { \%RSD of Area at 100\% } \\
\text { level }\end{array}$ \\
\hline \multirow{3}{*}{$\begin{array}{c}\text { Column temperature } \\
\left( \pm 5^{\circ} \text { C of set temperature }\right)\end{array}$} & At $35^{\circ} \mathrm{C}$ & 2.94 & 2.72 \\
\cline { 2 - 4 } & At $45^{\circ} \mathrm{C}$ & 3.64 & 3.17 \\
\hline $\begin{array}{c}\text { Flow-rate } \\
( \pm 0.1 \mathrm{~mL} \text { of set flow })\end{array}$ & At $0.9 \mathrm{~mL} / \mathrm{min}$ & 3.85 & 3.66 \\
\cline { 2 - 4 } & At $1.1 \mathrm{~mL} / \mathrm{min}$ & 2.56 & 3.42 \\
\hline
\end{tabular}

\section{CONCLUSION}

The proposed method is a direct tandem mass spectrometric method for screening and quantification of Ethyl Benzene Sulfonate (EBS) in the Amlodipine Besylate drug substances. This method utilizes SIM mode for quantification which provides better selectivity and sensitivity. The described analytical method is costeffective, direct, accurate and convenient quality control tool for determination of EBS in Amlodipine Besylate. The advantage of this method lies in its improved sensitivity and simpler sample preparation technique to those previously reported methods. SIM mode allows drastic reduction or elimination of matrix effects that limits the accuracy and detection limits. This method can be applied for the analysis of EBS in other drug substances.

\section{ACKNOWLEDGEMENT}

Author acknowledges the support of the coauthor Suryakala Duvvuri, B.M. Rao in conducting the research work and developing this manuscript.

\section{CONFLICT OF INTEREST}

Authors disclose no conflict of interest.

\section{REFERENCES}

[1] The Merck Index, An Encyclopedia of Chemicals, Drugs, and Biologicals, fourteenth ed., Merck \& Co., Inc, Whitehouse Station, New Jersey, 2006 monograph 491, 83.

[2] Goldmann S, Stoltefuss J, Born L. Determination of the absolute configuration of the active amlodipine enantiomer as (-) -(S): a correction, Journal of medicinal chemistry, 35, 1992, 3341-3344.

[3] Thacker H.P. S-amlodipine - The 2007 clinical review, Journal of Indian Medical Association, 105, 2007, 180190.

[4] Elder D, Facchine K.L, Levy J.N, Parsons R,Ridge D, Semo L, Teasdale A. An Approach to Control Strategies for Sulfonate Ester Formation in Pharmaceutical Manufacturing Based on Recent Scientific Understanding, Organic Process Research Development, 16, 2012, 1707-1710.

[5] European Directorate for Quality of Medicines and Healthcare. Enquiry: Alkyl Mesylate (Methane sulfonate) 
Impurities in Mesylate Salts, PharmaEuropa, 12, 2000, 91-108.

[6] Mesylate Ester Type Impurities Contained in Medicinal Products; Swissmedic, Department for Control of the Medicinal Products Market: Berne, Switzerland, October 23, 2007.

[7] Guideline on the Limits of Genotoxic Impurities, Committee for Medicinal Products for Human Use (CHMP), European Medicines Agency (EMEA), London, 28 June, 2006 (CPMP/SWP/5199/02, EMEA/CHMP/QWP/251344/2006).

[8] Guo T, Shi Y, Zheng L, Feng F, Zheng F, Liu W. Rapid and simultaneous determination of sulfonate ester genotoxic impurities in drug substance by liquid chromatography coupled to tandem mass spectrometry: comparison of different ionization modes. Journal of Chromatography A, 1355, 2014, 7379.

[9] Genotoxic and carcinogenic impurities in drug substances and products: recommended approaches. U.S. Department of Health and Human Services, Food and Drug Administration, Center for Drug Evaluation and Research (CDER), Silver Spring, MD, USA, December 2008.

[10] Kroes R, Renwick A.G, Cheeseman M, Kleiner J, Mangelsdorf I, Piersma A,
Schilter B, Sclatter J, Van Schothorst F, Vos G.J, Wurtzen G, Structurebased thresholds of toxicological concern (TTC): guidance for application to substances present at low levels in the diet, Food and Chemical Toxicology, 42, 2004,65-83.

[11] International Conference on Harmonization of Technical Requirements for the Registration of Pharmaceuticals for Human Use (ICH), Guideline Q2 (R1)-Validation of Analytical Procedures: Test and Methodology, 2005. 